\title{
Quantifying Conflict of Interest in the Choice of Anti-VEGF Agents
}

This article was published in the following Dove Press journal:

Clinical Ophthalmology

\author{
David J Browning ' \\ Paul B Greenberg ${ }^{2}$ \\ 'Charlotte, Eye, Ear, Nose, and Throat \\ Associates, Charlotte, NC, 28210, USA; \\ ${ }^{2}$ Division of Ophthalmology, Alpert \\ Medical School, Brown University, \\ Providence, RI, USA
}

Purpose: To quantify the economic incentives associated with the choice of anti-VEGF drugs for retinal diseases.

Methods: An economic model was created based on the distribution of use and number of injections of bevacizumab (B), versus aflibercept or ranibizumab (AR); published Medicare reimbursement rates; published rebates; estimated unreimbursed drug use; estimated use of drug company samples; and published costs-of-drugs. Differential economic incentives associated with the choice of drugs were calculated over a range of distributions of drug use. Results: The splits in drug choice ranged from $92 \% \mathrm{AR} / 8 \% \mathrm{~B}$ to $31 \% \mathrm{AR} / 69 \% \mathrm{~B}$, and in annual injection numbers from 2000 to 6000 with a median of 4000 in one 5-person retina service. Assumed values for rebates were 1\% for drug company rebate, $1 \%$ for group purchasing organization rebate, and 5 for number of unreimbursed injections per year. The differential economic incentive of a $92 \% \mathrm{AR} / 8 \%$ B split compared to a $31 \% \mathrm{AR} / 69 \% \mathrm{~B}$ split for the median annual number of injections was $\$ 266,893$.

Conclusion: Using real-world data, the economic incentive associated with a choice of more expensive anti-VEGF drugs is large. Accounting for unreimbursed drug use and the cost of additional staff required to manage expensive drug inventory does not nullify the incentive. To what degree this financial incentive influences ophthalmologists' choice of drugs is unknown, but not trivial. Financial disclosure of the conflicts of interest in the drugs recommended for treatment should be discussed with patients.

Keywords: anti-vascular endothelial growth factor agents, conflict of interest, economic incentives

The number of intravitreal injections of anti-vascular endothelial growth factor (VEGF) agents for neovascular macular degeneration, diabetic retinopathy, and retinal vein occlusions has grown rapidly in the past 20 years from 0.25 million in 2005 to 5.9 million in 2016 with continued growth to the present. ${ }^{1}$ In 2019 , the market value of anti-VEGF drugs in United States was $\$ 6.4$ billion. ${ }^{2}$ Given the volume and economic value of this activity, the factors that influence physician choice of drug are worth examining from a public health perspective.

Many factors influence the decision of which anti-VEGF drug to use including efficacy, safety, FDA approval status, legal risk; acquisition, inventory, and storage cost and risk; and economic reward. Although there continues to be a debate about the relative efficacy of anti-VEGF drugs, for the most part, they have been shown in multiple studies to be equally effective and safe in the treatment of neovascular macular degeneration, diabetic macular edema, and retinal vein occlusions. ${ }^{3-5}$ However, bevacizumab is not FDA-approved for intraocular use, whereas 
aflibercept and ranibizumab are. Ophthalmic bevacizumab is repackaged by compounding pharmacies from larger vials meant for oncologic use, and published examples of contamination during this step may influence choice. ${ }^{6}$

A potential conflict of interest (COI) is inherent in the ophthalmologist's choice of anti-vascular endothelial growth factor (VEGF) agents for the treatment of retinal vascular disease. ${ }^{7}$ The three drugs commonly used-aflibercept, bevacizumab, and ranibizumab-vary widely in cost and reimbursement by payers, such that the choice of which drug to use has financial consequences for physicians. ${ }^{6}$ These consequences could influence drug choice. ${ }^{7}$

The purpose of this paper is to quantify the economic COI that may influence ophthalmologists' choice of antiVEGF agent.

\section{Methods}

This study was an economic modeling study not involving the use of human subjects and therefore did not require institutional review board approval. It did not use protected health information and conformed to the tenets of the Helsinki Declaration. We quantified the COI based on nonconfidential information from one author's (DJB) retina practice and published information on drug costs and reimbursements. This required a two-pronged approach: defining (a) the key variables and (b) the categories of differential economic benefits for the anti-VEGF agents.

\section{Variables}

First, we determined the number of intravitreal injections per ophthalmologist per year. This was estimated from a group of five full-time retinal surgeons and rounded to the nearest thousand (range: 2000 to 6000 injections/year; median 4000).

Second, we determined the split in choice of drugs used. As the cost and mark-up for ranibizumab and aflibercept are similar, in the interest of simplicity, we dichotomized the choice of drug into the less expensive bevacizumab (B) or the more expensive drugs aflibercept or ranibizumab (AR); the costs and revenue for use of ranibizumab and aflibercept were assumed to be the same. There are small differences, but they do not alter the thrust of the calculation. We modeled a range of splits including 100\% AR: $0 \% \mathrm{~B}, 80 \%$ AR: $20 \% \mathrm{~B}, 60 \% \mathrm{AR}$ : $40 \%$ B, $40 \%$ AR: $60 \%$ B, 20\% AR: $80 \%$ B, and $0 \%$ AR: $100 \% \mathrm{~B}$. This will encompass all the range of splits possible in practice. To achieve specificity, as an example, the splits in choice of drugs ranged from 92\% AR: $8 \% \mathrm{~B}$ to $31 \%$ AR: $69 \% \mathrm{~B}$ in the practices of the five retina specialists sampled.

Third, we determined the cost of the drugs used. To understand the factors that influence drug cost to the physician, it is necessary to understand the infrastructure for physician-administered drugs (Figure 1). ${ }^{8}$ Physicians pay group purchasing organizations (GPOs), wholesalers, and drug companies. Physicians receive reimbursement

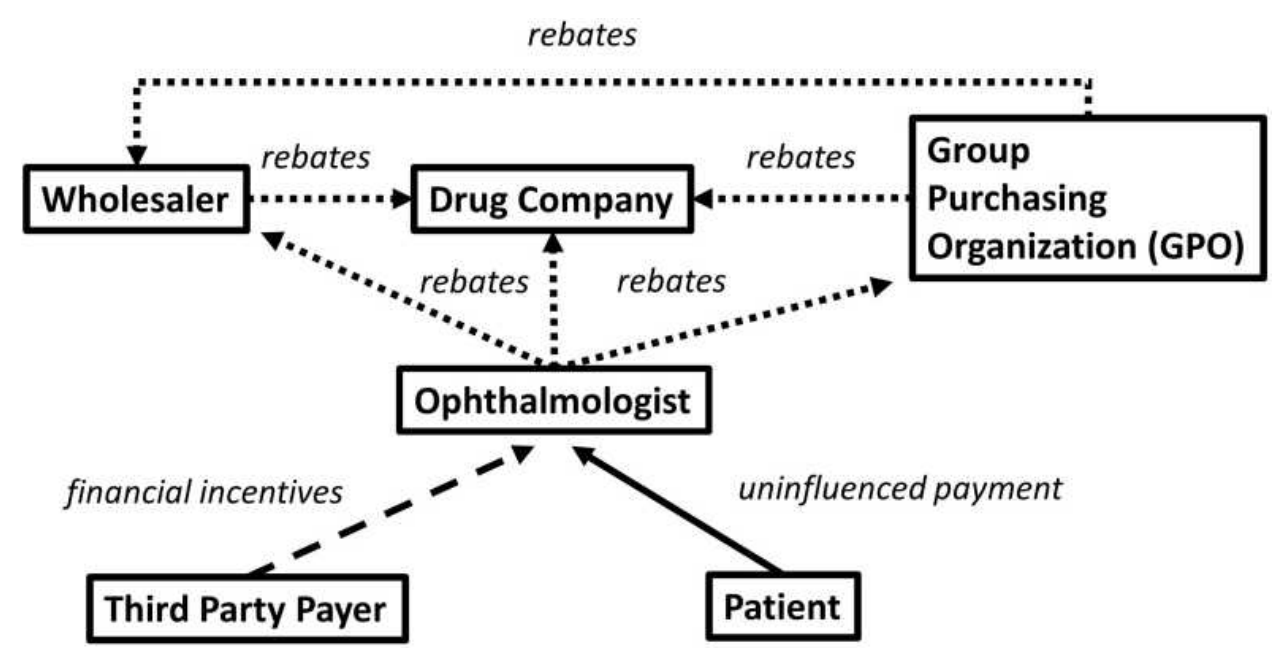

Figure I Diagram of the flow of payments involved in anti-vascular endothelial drug factor drugs in ophthalmology. The arrowheads indicate the direction of the payments. Thus, the third-party payers and the patients pay the ophthalmologist, but the ophthalmologist pays group purchasing organizations, wholesalers, and drug companies. Solid arrows depict straightforward uninfluenced payments. The dashed arrow-line indicates that third-party payers can provide financial incentives to ophthalmologists to choose one drug over another (eg, certain payers financially incentivize ophthalmologists to use bevacizumab rather than aflibercept or ranibizumab). The dotted arrows indicate that drug companies, group purchasing organizations (GPOs), and wholesalers can incentivize purchases of certain drugs by rebates (eg, there is no drug company rebate for bevacizumab, but there is for aflibercept and ranibizumab). Data from Fein. ${ }^{8}$ 
from Medicare, Medicaid, and private payers, and can receive rebates or discounts from the GPOs, wholesalers, and drug companies. The costs of drugs quoted in the literature vary, ${ }^{6,9,10}$ but we assumed costs of $\$ 40$ and $\$ 1900$ for B and AR, respectively, which are values within the published ranges. The cost of $B$ is not affected by rebates, because there are no rebates for $\mathrm{B}$. There are rebate programs from the pharmaceutical companies based on volumes used for AR. ${ }^{11}$ These rebates are contractually confidential, but published values range from $1 \%$ to $3.5 \% .^{9,11}$ To be conservative, we used the $1 \%$ figure for the calculation. The rebates obtained from GPOs and wholesalers also vary, but to arrive at a lower bound for economic incentive, we used a $1 \%$ figure for the calculation. Therefore, the costs assumed in the calculation were $\$ 40$ and $\$ 1862$ for $B$ and AR, respectively. The cost for AR with these assumptions is $\$ 38$ less than the wholesale average cost, which is close to the difference of $\$ 41$ quoted elsewhere. ${ }^{9}$

\section{Differential Economic Benefits}

The first category of differential economic benefit arises from differences in markup for the different agents. For the purposes of the calculation, the reimbursement for $\mathrm{B}$ and $\mathrm{AR}$ will be assumed to be that provided by Medicare, which will be conservative, as some proportion of patients are covered by private insurance, which reimburses at a higher rate than Medicare. Medicare reimbursement after sequestration is the average sale price (ASP) with a markup of $4.3 \%$ of the average sale price to compensate for inventory costs. The ASP for B is the same as the cost - \$40. The ASP for AR is less than the cost because of the spectrum of discounts and rebates. We used an average discount of $\$ 41$ as used elsewhere, ${ }^{9}$ for an ASP of $\$ 1859$ for AR. Thus, the Medicare reimbursement for AR is \$41.72 and \$1938.94 for B and AR, respectively. Table 1 presents the differential profit per injection for the various modeled splits in drug use. As a concrete example, for an ophthalmologist performing 4000 intravitreal injections per year, the difference in profit between a drug choice split of 92:8 and 31:69 is $\$ 183,537$, incentivizing the use of AR.

The second category of differential economic benefit concerns samples provided by drug companies. No samples of bevacizumab are available, because no drug company promotes bevacizumab's use, but the median number of samples of AR used in the course of the year is approximately 100 in the practice we studied. The face value of this number of samples is $\$ 186,200$. However, because the ophthalmologist cannot spend this money, it is not fungible with the other categories and will be excluded from the total spendable incentive. However, it may influence ophthalmologist behavior.

The third category of differential economic benefit is the rebate that accrues when the drugs are purchased with a credit card. This cash rebate varies with the type of credit card, but a typical rebate rate is $2 \%$, which will be used for the calculation. Table 2 presents the differential credit card rebates per injection for the various modeled splits in drug use. As a concrete example, for the median ophthalmologist performing 4000 injections/year, the range of rebates on a $92: 8$ to $31: 69$ split of drug choice would be $\$ 137,299$ and $\$ 48,386$, respectively, with a differential rebate of $\$ 88,914$ incentivizing AR use.

The fourth category of differential economic impact is the cost of unreimbursed administered drugs. The ophthalmologist purchases the drug, administers it, and sometimes

Table I Differential Profit per Injection for Different Splits of Anti-Vascular Endothelial Growth Factor Drug Choice for Two Ophthalmologists Performing the Same Number of Injections per Year

\begin{tabular}{|l|l|l|l|l|l|l|}
\hline & I00\%AR:0\%B & 80\%AR:20\%B & 60\%AR:40\%B & 40\%AR:60\%B & 20\%AR:80\%B & 0\%AR: 100\%B \\
\hline I00\%AR:0\%B & 0 & -15.04 & -30.28 & -45.13 & -60.18 & -75.22 \\
80\%AR:20\%B & 15.04 & 0 & -15.24 & -30.09 & -45.13 & -60.18 \\
60\%AR:40\%B & 30.28 & 15.24 & 0 & -14.85 & -29.90 & -44.94 \\
40\%AR:60\%B & 45.13 & 30.09 & 14.85 & 0 & -15.04 & -30.09 \\
20\%AR:80\%B & 60.18 & 45.13 & 29.90 & 15.04 & 0 & -15.04 \\
0\%AR:100\%B & 75.22 & 60.18 & 44.94 & 30.09 & 15.04 & 0 \\
\hline
\end{tabular}

Notes: Each column represents an ophthalmologist whose split of anti-vascular endothelial growth factor (anti-VEGF) drug choice is characterized in the top cell of the column. Each row represents a separate, comparator ophthalmologist whose split of anti-VEGF drug choice is characterized in the left-hand cell of the row. Each cell of the table lists the differential profit comparing the row ophthalmologist with the column ophthalmologist corresponding to that cell of the table. The units of the cell entries are dollars. For example, the cell at the intersection of the third row and second column compares a drug split of $60 \% A R: 40 \% B$ (the third row) to a drug split of I00\%AR:0\%B (the second column). The cell value, 30.28, means that the ophthalmologist who uses AR $100 \%$ of the time earns $\$ 30.28$ per injection more than the ophthalmologist who uses AR $60 \%$ of the time and B $40 \%$ of the time. All diagonal cells have values of 0 , because diagonal cells compare ophthalmologists with identical splits. A negative cell value implies that the column ophthalmologist earns less per injection than the row ophthalmologist corresponding to the cell. The diagonal is an axis of symmetry. 
Table 2 Differential Credit Card Rebates per Injection for Different Splits of Anti-Vascular Endothelial Growth Factor Drug Choice for Two Ophthalmologists Performing the Same Number of Injections per Year

\begin{tabular}{|l|l|l|l|l|l|l|}
\hline & I00\%AR:0\%B & 80\%AR:20\%B & 60\%AR:40\%B & 40\%AR:60\%B & 20\%AR:80\%B & 0\%AR: I00\%B \\
\hline I00\%AR:0\%B & 0 & -7.29 & -14.58 & -21.88 & -29.15 & -36.44 \\
80\%AR:20\%B & 7.29 & 0 & -7.29 & -14.58 & -21.86 & -29.15 \\
60\%AR:40\%B & 14.58 & 7.29 & 0 & -7.29 & -14.58 & -21.86 \\
40\%AR:60\%B & 21.88 & 14.58 & 7.29 & 0 & -7.29 & -14.58 \\
20\%AR:80\%B & 29.15 & 21.86 & 14.58 & 7.29 & 0 & -7.29 \\
0\%AR:100\%B & 36.44 & 29.15 & 21.86 & 14.58 & 7.29 & 0 \\
\hline
\end{tabular}

Notes: Each column represents an ophthalmologist whose split of anti-vascular endothelial growth factor (anti-VEGF) drug choice is characterized in the top cell of the column. Each row represents a separate, comparator ophthalmologist whose split of anti-VEGF drug choice is characterized in the left-hand cell of the row. Each cell of the table lists the differential profit comparing the row ophthalmologist with the column ophthalmologist corresponding to that cell of the table. The units of the cell entries are dollars. For example, the cell at the intersection of the third row and second column compares a drug split of $60 \% \mathrm{AR}: 40 \% \mathrm{~B}$ (the third row) to a drug split of I00\%AR:0\%B (the second column). The cell value, 14.58 , means that the ophthalmologist who uses AR $100 \%$ of the time earns $\$ 14.58$ per injection more than the ophthalmologist who uses AR $60 \%$ of the time and B $40 \%$ of the time. All diagonal cells have values of 0 , because diagonal cells compare ophthalmologists with identical splits. A negative cell value implies that the column ophthalmologist earns less per injection than the row ophthalmologist corresponding to the cell. The diagonal is an axis of symmetry.

fails to receive reimbursement due to administrative errors such as failure to obtain preauthorization from a payer. ${ }^{6}$ In such cases, the cost of the drug is written off. Drug companies attempt to mitigate this difficulty by providing samples that can be used in cases the ophthalmologist suspects to be at higher risk for reimbursement default, but the problem still exists. Based on the experience of the practice studied, the median number of written-off injections is estimated to be 5 per year per ophthalmologist. Table 3 presents the differential economic impact of unreimbursed administered drugs for the various modeled splits in drug use. As a concrete example, the range of expense on a 92:8 to 69:31 split of drug choice would be $\$ 8581$ to $\$ 3024$, with a differential expense of $\$ 5557$ penalizing the higher AR user. Data on written-off drug costs is sparse and anecdotal, but newer methods of inventory control such as the Physician Office Drug Inventory
System (PODIS) have probably reduced these costs, and may be a factor in the decreasing use of B and increasing use of AR. ${ }^{6}$

\section{Results}

Adding up the economic impact of the spendable components of drug choice yields a median differential financial impact to an ophthalmologist of $\$ 266,893$ per year (Table 4). Hiring one or two additional staff to manage preauthorizations and inventory control does not overcome the financial incentives to choose the expensive drugs. The incentive would be greater if an ophthalmologist used all AR, would be less if one used all B (Table 1); would be greater if the ophthalmologist had to write off fewer injections and less if one wrote off more; and would be greater by an unquantifiable amount if one used more samples, and less if one used fewer samples. Drug companies

Table 3 Differential Economic Impact of Unreimbursed Administered Drugs per Injection for Different Splits of Anti-Vascular Endothelial Growth Factor Drug Choice for Two Ophthalmologists Performing the Same Number of Injections per Year

\begin{tabular}{|l|l|l|l|l|l|l|}
\hline & I00\%AR:0\%B & 80\%AR:20\%B & 60\%AR:40\%B & 40\%AR:60\%B & 20\%AR:80\%B & 0\%AR: 100\%B \\
\hline I00\%AR:0\%B & 0 & 0.46 & 0.91 & 1.37 & 1.82 & 2.28 \\
80\%AR:20\%B & -0.46 & 0 & 0.46 & 0.91 & 1.37 & 1.82 \\
60\%AR:40\%B & -0.91 & -0.46 & 0 & 0.46 & 0.91 & 1.37 \\
40\%AR:60\%B & -1.37 & -0.91 & -0.46 & 0 & 0.46 & 0.91 \\
20\%AR:80\%B & -1.82 & -1.37 & -0.91 & -0.46 & 0 & 0.46 \\
0\%AR:100\%B & -2.28 & -1.82 & -1.37 & -0.91 & -0.46 & 0 \\
\hline
\end{tabular}

Notes: Each column represents an ophthalmologist whose split of anti-vascular endothelial growth factor (anti-VEGF) drug choice is characterized in the top cell of the column. Each row represents a separate, comparator ophthalmologist whose split of anti-VEGF drug choice is characterized in the left-hand cell of the row. Each cell of the table lists the differential profit comparing the row ophthalmologist with the column ophthalmologist corresponding to that cell of the table. The units of the cell entries are dollars. For example, the cell at the intersection of the third row and second column compares a drug split of $60 \%$ AR:40\%B (the third row) to a drug split of I00\%AR:0\%B (the second column). The cell value, -0.91 , means that the ophthalmologist who uses AR $100 \%$ of the time earns $\$ 0.91$ per injection less (signified by the minus sign) than the ophthalmologist who uses AR $60 \%$ of the time and B $40 \%$ of the time. All diagonal cells have values of 0 , because diagonal cells compare ophthalmologists with identical splits. A negative cell value implies that the column ophthalmologist earns less per injection than the row ophthalmologist corresponding to the cell. The diagonal is an axis of symmetry. The assumed number of injections per year for the data displayed is 4000 . 
Table 4 Calculation of One-Year Differential Financial Impact Based on Ophthalmologist's Choice of Anti-Vascular Endothelial Growth Factor Drug

\begin{tabular}{|c|c|c|}
\hline Variable & Assumed Value & Comments on Calculation \\
\hline Number of injections per year $(\mathrm{N})$ & 4000 & Median value from 5 - person retina service \\
\hline Cost of bevacizumab (CB) & $\$ 40$ & Published data \\
\hline Cost of aflibercept/ranibizumab (CAR) & $\$ 1862$ & Published data \\
\hline Reimbursement for bevacizumab (RB) & $\$ 41.72$ & Assume a $4.3 \%$ markup from average sale price \\
\hline Reimbursement for aflibercept/ranibizumab (RAR) & $\$ 1938.94$ & Assume a $4.3 \%$ markup from average sale price \\
\hline Split of drugs for a high AR user (HS) & $92 \%: 8 \%$ & Split for highest AR user in a 5 -person retina service \\
\hline Split of drugs for a low AR user (LS) & $31 \%: 69 \%$ & Split for lowest $A R$ user in a 5 -person retina service \\
\hline Profit on drugs for a high AR user (PHS) & $\$ 283,690$ & $=0.92 * N * R A R+0.08 * N * R B-0.92 * N * C A R-0.08 * N * C B$ \\
\hline Profit on drugs for a low AR user (PLS) & $\$ 100,153$ & $=0.31 * \mathrm{~N} * \mathrm{RAR}+0.69 * \mathrm{~N} * \mathrm{RB}-0.3 \mathrm{I} * \mathrm{~N} * \mathrm{CAR}-0.69 * \mathrm{~N} * \mathrm{CB}$ \\
\hline Credit card rebate for a high AR user (CCHS) & $\$ 137,299$ & $=0.02 *(.92 * \mathrm{~N} * \mathrm{CAR}+0.08 * \mathrm{~N} * \mathrm{CB})$ \\
\hline Credit card rebate for a low AR user (CCLS) & $\$ 48,386$ & $=0.02 *(.3 \mathrm{I} * \mathrm{~N} * \mathrm{CAR}+0.69 * \mathrm{~N} * \mathrm{CB})$ \\
\hline Financial loss from written-off drugs for a high AR user (WHS) & $\$ 8581$ & $=5 * .92 * \mathrm{CAR}+5 * .08 * \mathrm{CB}$ \\
\hline Financial loss from written-off drugs for a low AR user (WLS) & $\$ 3024$ & $=5 * .31 * C A R+5 * .69 * C B$ \\
\hline Differential financial impact for a high versus a low AR user & $\$ 266,893$ & $=\mathrm{PHS}+\mathrm{CCHS}-\mathrm{WHS}-\mathrm{PLS}-\mathrm{CCLS}+\mathrm{WLS}$ \\
\hline
\end{tabular}

Notes: The number of injections per year (4000) is an estimated median based on a retina service of 5 ophthalmologists from DJB's practice. The number of written-off injections per year (5) is an estimated median based on a retina service of 5 ophthalmologists from DJB's practice. The values in the last 7 rows have been rounded to the nearest dollar.

believe that rebates influence physicians' behavior, which is why they offer them. ${ }^{12}$ When brolucizumab was recently approved by the FDA for use in neovascular macular degeneration, the rebates for aflibercept use for some high-volume users were raised (personal experience).

\section{Discussion}

Society trusts physicians to recommend drugs that will benefit their patients the most, uninfluenced by the financial consequences to the physician. However, it is widely recognized that physicians are not immune to economic COIs. ${ }^{12-15}$ This study suggests there is a significant economic incentive to use the expensive anti-VEGF drugs. While this incentive probably plays some role in ophthalmologists' choice of medication, it would be challenging to determine the magnitude of its effect on their behavior, as there are many factors that enter into the choice of antiVEGF therapy, such as FDA-approval status, perceived legal risk, and risk of compounding error. There are other economic incentives not covered here that are provided by pharmaceutical companies to encourage the use of their drugs, including payments to a charitable foundation earmarked to defray out-of-pocket costs for patients to use aflibercept. ${ }^{16}$

This study has limitations. Physicians employed in academic practices and by the government do not receive rebates, and employed physicians in private settings also may have no financial incentives tied to drug choice. We modeled differential financial incentives over the whole range of potential splits in drug use and provided a concrete example based on one 5 -person retina group. Real-world data on the splits in anti-VEGF drug use has not been published, but it is known that bevacizumab use is diminishing, and aflibercept-ranibizumab us is increasing. ${ }^{15}$ One hypothesis is that the financial disadvantage to the physician for using bevacizumab was amplified by the shift from insulin to silicone-free syringes, increasing costs with no commensurate increase in reimbursement. ${ }^{15}$

None of the elements cited as potentially influencing behavior-choice of drug, differential inventory reimbursement, credit card rebate, or volume rebates from drug companies-is illegal, yet there is significant debate about the ethics of the practices mentioned. ${ }^{17}$ In the spirit of the American Academy of Ophthalmology Code of Ethics and the Sunshine Act, one standard would be to require financial disclosure by the ophthalmologists making recommendations to their patients. ${ }^{13,18,19}$ This would require a meaningful discussion. Unlike a disclosure for a scientific meeting or peer-reviewed publication, the target is not a professional peer but a patient who is dependent on the physician has an inferior fund of relevant knowledge and has a higher personal stake in the outcome of the communication. Disclosure has been recognized to be an important aspect in managing conflict of interest in scientific presentations, but 
insufficient. ${ }^{20,21}$ Nevertheless, it is the first step and has not been taken in patient relations regarding the ophthalmologist's choice of anti-VEGF drugs.

There has been little discussion among ophthalmologists about having this disclosure conversation with patients. However, as anti-VEGF medications of similar efficacy but widely different cost and reimbursement are not going away, that discussion should start soon.

\section{Disclosure}

DJB received grant support from the DRCR network, Genentech, Regeneron, Novartis, Apellis, book royalties from Springer, Inc. and has equity ownership in Zeiss Meditec, Inc. $(<\$ 25,000)$. The authors report no other conflicts of interest in this work.

\section{References}

1. Williams GA. IVT injections: health policy implications. Review of ophthalmology 2014. Ophthalmology. 2014;21(6):62-64.

2. Market for anti-VEGF drugs in USA; 2019. Available from: https:// eyewire.news/articles/market-scope-novartis-leads-the-race-to-launch -a-new-anti-vegf-for-wet-amd/. Accessed December 14, 2020.

3. Martin DF, Maquire MG, Fine SL, et al. Ranibizumab and bevacizumab for treatment of neovascular age-related macular degeneration. Two-year results. Ophthalmology. 2012;119(7):1388-1398. doi:10.1016/j.ophtha.2012.03.053

4. Wells JA, Glassman AR, Ayala AR, et al.; for the Diabetic Retinopathy Clinical Research Network. Aflibercept, bevacizumab, or ranibizumab for diabetic macular edema. Two-year results from a comparative effectiveness randomized clinical trial. Ophthalmology. 2016;123 (6):1351-1359. doi:10.1016/j.ophtha.2016.02.022

5. Sangroongruangsri S, Ratanapakorn T, Wu O, Anothaisintawee T, Chaikledkaew U. Comparative efficacy of bevacizumab, ranibizumab, and aflibercept for treatment of macular edema secondary to retinal vein occlusion: a systematic review and network meta-analysis. Expert Rev Clin Pharmacol. 2018;11(9):903-916. doi:10.1080/ 17512433.2018.1507735

6. Baker-Schena L. Expensive drugs. EyeNet. 2017;(44).

7. Mahr MA, Hodge DO, Erie JC. Association between industry payments and anti-vascular endothelial growth factor use in medicare beneficiaries. Ophthalmol Retin. 2017;1(1):19-24. doi:10.1016/j. oret.2016.08.001
8. Fein AJ. The 2016-2017 economic report on pharmaceutical wholesalers and specialty distributors; 2017. Available from: https://drug channelsinstitute.com/files/2017-18-PharmaceuticalWholesalersOverview.pdf. Accessed February 27, 2021.

9. Jain A, Varshney N. Economics of intravitreal medications for neovascular AMD. Retin Physician. 2014;11(1):30-70.

10. Hutton DW, Stein JD, Glassman AR, et al. Five year cost effectiveness of intravitreous ranibizumab therapy vs panretinal photocoagulation for treating proliferative diabetic retinopathy: a secondary analysis of a randomized clinical trial. JAMA Ophthalmol. 2019;137 (12):1424-1432. doi:10.1001/jamaophthalmol.2019.4284

11. Pollack A. Genentech offers secret rebates for eye drug. New York Times. 2010 Nov 3;Business.

12. Lichter PR. Debunking myths of physician-industry conflicts of interest. Am J Ophthalmol. 2008;146(2):159-171. doi:10.1016/j. ajo.2008.04.007

13. Richardson E. The physician payments sunshine act. Health affairs 2014; 2014. https://www.healthaffairs.org/do/10.1377/hpb20141002. 272302/full/healthpolicybrief_127.pdf. Accessed February 27, 2021.

14. Kelly J, Bhatt S, Aten A, et al. Cost of care initiative: analyzing a least cost alternative program with specialty ophthalmic injections under the medical benefit. J Manag Care Spec Pharm. 2018;24:S105.

15. Glasser DB, Parikh R, Lum F, Williams GA. Intravitreal anti-vascular endothelial growth factor cost savings achievable with increased bevacizumab reimbursement and use. Ophthalmology. 2020;127 (12):1688-1692. doi:10.1016/j.ophtha.2020.06.012

16. Loftus P. U.S. suit alleges regeneron kickbacks. Wall Street Journal. 2020 Jun 25;Business, Healthcare, and Health.

17. Fleck LM, Danis M. How should therapeutic decisions about expensive drugs be made in imperfect environments? AMA $J$ Ethics. 2017;19(2):147-156.

18. Chang JS. The physician payments sunshine act: data evaluation regarding payments to ophthalmologists. Ophthalmology. 2015;122 (4):656-661. doi:10.1016/j.ophtha.2014.11.003

19. American Academy of Ophthalmology Code of Ethics; 2021. Available from: https://www.aao.org/ethics-detail/code-ofethics\#commercial. Accessed February 21, 2021.

20. Horstman AA, Niziol LM, Lichter PR, Lichter PR. Association of mandatory disclosure policies and laws with physician-industry financial relationships. JAMA Ophthalmol. 2019;137(5):523-530. doi:10.1001/jamaophthalmol.2019.0085

21. Dorman T. Disclosure as only a single piece of the puzzle. JAMA Ophthalmol. 2019;137(5):530-531. doi:10.1001/jamaophtha lmol.2019.0090
Clinical Ophthalmology

\section{Publish your work in this journal}

Clinical Ophthalmology is an international, peer-reviewed journal covering all subspecialties within ophthalmology. Key topics include: Optometry; Visual science; Pharmacology and drug therapy in eye diseases; Basic Sciences; Primary and Secondary eye care; Patient Safety and Quality of Care Improvements. This journal is indexed on PubMed
Central and CAS, and is the official journal of The Society of Clinical Ophthalmology (SCO). The manuscript management system is completely online and includes a very quick and fair peer-review system, which is all easy to use. Visit http://www.dovepress.com/ testimonials.php to read real quotes from published authors.

\section{Dovepress}

